\title{
Orthodontic Treatment Need and Complexity among Nigerian Adolescents in Rivers State, Nigeria
}

\author{
Elfleda Angelina Aikins, ${ }^{1}$ Oluranti Olatokunbo daCosta, ${ }^{2}$ \\ Chukwudi Ochi Onyeaso, ${ }^{3}$ and Michael Chukwudi Isiekwe ${ }^{2}$
}

${ }^{1}$ Department of Child Dental Health, Dental Centre, University of Port Harcourt Teaching Hospital, Port Harcourt 500001, Nigeria

${ }^{2}$ Department of Child Dental Health, School of Dentistry, College of Medicine, University of Lagos, Lagos 101241, Nigeria

${ }^{3}$ Department of Child Dental Health, Faculty of Dentistry, College of Health Sciences, University of Port Harcourt, Port Harcourt 500001, Nigeria

Correspondence should be addressed to Elfleda Angelina Aikins, elfledaaikins@yahoo.com

Received 9 July 2011; Revised 7 September 2011; Accepted 13 September 2011

Academic Editor: Stephen Richmond

Copyright (๑) 2011 Elfleda Angelina Aikins et al. This is an open access article distributed under the Creative Commons Attribution License, which permits unrestricted use, distribution, and reproduction in any medium, provided the original work is properly cited.

\begin{abstract}
Introduction. The assessment of orthodontic treatment need and complexity are necessary for informed planning of orthodontic services. The aim of this cross-sectional study was to assess these parameters using the Index of Complexity, Outcome, and Need (ICON) in a Nigerian adolescent population in a region where orthodontic services are just being established. Methods. Six hundred and twelve randomly selected Nigerian adolescents aged 12 to 18 years were examined using the ICON in their school compounds. Descriptive statistics were employed in the data analysis. Results. Out of a total of $38.1 \%$ of the population found to need orthodontic treatment, there were more males and older adolescents. The overall mean ICON score for the population was $39.7 \pm 25.3$ SD with males having statistically higher mean ICON score. The grades of complexity of the population were $21.6 \%$ for very difficult and difficult, 7.5\% moderate, and 70.9\% mild/easy. Conclusions. Although just over a third of the adolescents were found to have a need for treatment, about a quarter of them were found to have difficult and very difficult complexity grades indicating a need for specialist care. The authors recommend the training of more specialist orthodontists in this region.
\end{abstract}

\section{Introduction}

The assessment of orthodontic treatment need and complexity is necessary for the planning of orthodontic services in any given population, as well as training programmes for specialists [1]. Occlusal indices, such as the Index of Orthodontic Treatment Need (IOTN) [2] and the Dental Aesthetic Index (DAI) [3] have been used successfully around the world to provide information on orthodontic treatment need in various communities.

Richmond et al. [4] suggested that difficulty and complexity in orthodontics are synonymous and should be defined as a measurement of skill and effort while severity is a measurement of how far a malocclusion deviates from the normal. Meanwhile, Cassinelli et al. [5] also reported that complexity or difficulty is related to the severity of malocclusion and increases as the severity of the malocclusion increases.
The Index of Complexity, Outcome, and Need (ICON) [6] which was developed based on the expert opinions of 97 practising orthodontic specialists from 9 countries has provided an internationally acceptable means of measuring orthodontic treatment need, complexity and outcome with a single measurement protocol. The index comprises five components: The Aesthetic Component of the IOTN (AC), amount of maxillary crowding or spacing, the presence or absence of crossbite, incisor open bite/overbite, and anteroposterior buccal relationship which are weighted as follows: AC (7), maxillary crowding or spacing (5), crossbite (5), incisor overbite/open bite (4), and anteroposterior buccal relationship (3). The components are measured, multiplied by their respective weights, and summed up to give an overall score. The cut-off point for treatment need is an ICON score of 43. Complexity values are graded from easy to very difficult, depending on the score obtained. 
In Southwestern Nigeria, various studies have been carried out to assess the prevalence of malocclusion, though a large majority [7-14] were purely descriptive qualitative studies. Other studies on orthodontic treatment need have equally been done with the Index of Orthodontic Treatment Need (IOTN) and the Dental Aesthetic Index (DAI) [15-21]. Meanwhile the Index of Complexity, Outcome, and Need (ICON) has also been used to determine orthodontic treatment need and complexity both in the general population and in patients attending orthodontic clinics [22-24].

Generally, research, clinical practice, and specialist training in Southwestern Nigeria as it relates to orthodontics is much more advanced, as compared to Rivers State located in South-South Nigeria, where the specialty is relatively new. Outside the studies in Ibadan City of Nigeria, the authors search did not reveal any literature from other parts of Nigeria that assessed both orthodontic treatment need and complexity using the ICON.

Moreover, ICON has been validated for the Nigerian population, shown to be useful in assessing orthodontic treatment need and complexity $[22,23]$ and to be effective for assessment of different facets of orthodontic provision, when compared with previously existing indices [25]. Therefore, the aim of this epidemiological study was to estimate the need for and the complexity of orthodontic treatment among 12 to 18 year-old schoolchildren in Rivers State, Nigeria, using the ICON. This is the first time such a study is being carried out in this part of Nigeria, and documentation of such important statistics will thus allow for informed planning of orthodontic services in this region.

\section{Material and Methods}

There are 23 Local Government Areas (LGAs) in Rivers State of Nigeria Due to security concerns at the time this study was being carried out; permission was granted by the Rivers State Ministry of Education for 12 LGAs, comprising 2 urban and 10 rural, out of which six were selected by ballot, consisting of one urban LGA (Port Harcourt) and five rural LGAs: Ikwerre, Omumma, Tai, Okrika, and Asari-Toru.

Out of the list of schools obtained from the Rivers State Ministry of Education one school was selected by ballot from each of the six LGAs making a total of six schools. The students were randomly selected from each of the schools and the sample population consisting of 612 students with age range of 12 to 18 years was obtained comprising $299(48.9 \%)$ males and $313(51.1 \%)$ females. None of the students had undergone any form of orthodontic treatment.

The researcher was calibrated in the use of the ICON using dental casts by a senior colleague (COO) who is trained and experienced in the use of the index. An intraoral examination of the participating students was conducted by the researcher in the selected school compounds using natural illumination and strictly following the guidelines of the ICON. Disposable wooden spatulae and orthodontic millimetre rulers were used. The need for orthodontic treatment was defined as an ICON score of 43 and above while complexity was graded into easy $(<29)$, mild (29-50), moderate (51-63), difficult (64-77), and very difficult $(>77)$ in line with ICON guidelines.

2.1. Intraexaminer Reliability. Sixty-two of the students were selected randomly and reexamined by the researcher after a four-week interval. The two examinations were evaluated statistically.

The reproducibility of the ICON scores were assessed using Spearman's Rank Correlation Coefficient $(P=0.98)$, and excellent agreement was found. Intraexaminer consistency for the categorisation of treatment need into need and no need was expressed as the kappa reliability coefficient with a value of 0.93 indicating strong agreement, whilst the reliability of the complexity grades was also evaluated using W Kendall test with a value of 0.78 .

2.2. Statistical Analysis. The data was analyzed statistically using the SPSS statistical package (Statistical Package for the Social Sciences Version 17.0 for Windows 2009, SPSS, Inc., Chicago, Ill, USA).

2.3. Descriptive Statistics. The qualitative variable "gender" was described using frequencies and percentages. For the quantitative variable ICON score, mean for central tendency and standard deviation were used. For the ordinal variables, ICON categorization of treatment complexity, number (frequencies), and percentages were used for descriptive statistics.

2.4. Inferential Statistics. Male and female subject differences with respect to ICON score were tested using Student $t$-test. To test for any dependence on gender of "complexity grades," chi-square test was used.

\section{Results}

The mean age of the studied population was $15 \pm 2.0$ years; male was $14.9 \pm 1.9$ years and female was $15.0 \pm 2.0$.

3.1. Orthodontic Treatment Need. About thirty-eight per cent $(38.1 \%)$ of the studied population had a need for orthodontic treatment with a mean ICON score of $39.7 \pm$ 25.3. There were statistically significant gender differences, the mean ICON score was higher in males $(43.1 \pm 26.3)$ than females $(36.3 \pm 23.8)(P=0.001)$, and a higher number of males $(43.5 \%)$ than females $(32.9 \%)$ were found to be in need of orthodontic treatment (Table 1). Statistically significant age differences were also determined; twelve- and thirteen-year olds were less likely to have a treatment need (odd ratio $=0.58$ ), while 17 -year olds were found to be more likely to have need for orthodontic treatment (Odd ratio = 1.82) when compared with the other age groups $(P=0.04)$ (Table 2).

3.2. Orthodontic Treatment Complexity. The grades of orthodontic treatment complexity are shown in Figure 1. Easy complexity was found in $42.6 \%$ of the population, $28.3 \%$ had mild complexity, $7.5 \%$ moderate complexity, whilst $10.3 \%$ and $11.3 \%$ had difficult and very difficult grades of complexity, respectively. There were significant differences between complexity grades in males and females $(P=0.02)$ 
TABle 1: Assessment of orthodontic treatment need and complexity by gender according to the Index of Complexity, Outcome, and Need (ICON).

\begin{tabular}{lccc}
\hline Variable & \multicolumn{2}{c}{ Frequency $(\%)$} \\
Female
\end{tabular}

TABLE 2: Relationship between age, gender, and assessed orthodontic treatment need according to the Index of Complexity, Outcome, and Need.

\begin{tabular}{|c|c|c|c|c|c|c|c|}
\hline \multirow{2}{*}{ Variable } & \multicolumn{2}{|c|}{ ICON assessment of need (\%) } & \multirow{2}{*}{$\chi^{2}$} & \multirow{2}{*}{ Odd ratio } & \multicolumn{2}{|c|}{$95 \% \mathrm{CI}$} & \multirow{2}{*}{$P$} \\
\hline & Need $(n=233)$ & No need $(n=379)$ & & & Lower & Upper & \\
\hline \multicolumn{8}{|l|}{ Age (years) } \\
\hline 12 & $26(28.0)$ & $67(72.0)$ & 4.76 & 0.58 & 0.35 & 0.97 & $0.03^{*}$ \\
\hline 13 & $22(27.5)$ & $58(72.5)$ & 4.36 & 0.58 & 0.33 & 1.00 & $0.04 *$ \\
\hline 14 & $36(38.7)$ & $57(61.3)$ & 0.02 & 1.03 & 0.64 & 1.66 & 0.89 \\
\hline 15 & $34(45.3)$ & $41(54.7)$ & 1.91 & 1.41 & 0.84 & 2.36 & 0.17 \\
\hline 16 & $37(37.4)$ & $62(62.6)$ & 0.02 & 0.97 & 0.60 & 1.54 & 0.88 \\
\hline 17 & $54(50.0)$ & $54(50.0)$ & 7.91 & 1.82 & 1.17 & 2.82 & $0.01 *$ \\
\hline 18 & $24(37.5)$ & $40(62.5)$ & 0.01 & 0.97 & 0.55 & 1.71 & 0.92 \\
\hline \multicolumn{8}{|l|}{ Gender } \\
\hline Male & $130(43.5)$ & $169(56.5)$ & 7.25 & 1.57 & 1.11 & 2.21 & $0.01^{*}$ \\
\hline Female & $103(32.9)$ & $210(67.1)$ & 7.25 & 0.64 & 0.45 & 0.90 & $0.01^{*}$ \\
\hline
\end{tabular}

* Significant.

(Table 1 ), with twice as many males $(15.1 \%)$ with very difficult complexity grades as females $(7.7 \%)$ and more female $(47.3 \%)$ than male students $(37.8 \%)$ found to have easy categories of treatment need.

As the level of complexity of the malocclusion increased, a corresponding increase in treatment need was seen (Table 3). Of the students assessed to have a need for treatment $(38.1 \%)$, none of them was found to have malocclusions of easy complexity while students without a treatment need did not have malocclusion that was categorized to be difficult or very difficult to treat.

\section{Discussion}

The mean ICON score of $39.7 \pm 25.3$ obtained in this study was slightly lower than that obtained for a similar Nigerian population [24] of 12 - to 18-year olds $(41.93 \pm 15.38)$. However, this study involved a larger sample size, and thus a wider range of occlusion was assessed. Likewise, the mean
ICON score recorded in our study was also lower than the values obtained in prevalence studies on 12- and 13-year olds in Latvia (42.05) [26] and Senegal (42.31-44.46) [27] and 11-14 year-old Iranian schoolchildren $(44.6 \pm 24.83)$ [28]. These differences could be due to the wider age range of the population whilst racial variations may also be a factor.

Just over a third of the population in this epidemiological study was found to have a need for orthodontic treatment according to the ICON (38.1\%). This is comparable to the value $(35.3 \%)$ obtained for children in Latvia [26] but lower than $42 \%$ obtained for adolescents in Western Nigeria [24, 29], 44.1\% in Senegal [27], and 46.6\% reported among 1114 year-old Iranian schoolchildren [28]. Studies conducted on orthodontic patients, however, with values of $82.1 \%$ in Nigeria [23], 94\% and 86\% in Greece [30] and United States of America [25, 31], respectively, have a much higher need for treatment than obtained in this study. This is expected because these studies were clinic-based and involve patients 
TABle 3: Associations between orthodontic treatment need and complexity.

\begin{tabular}{|c|c|c|c|c|c|c|}
\hline \multirow{2}{*}{ Assessment according to the ICON } & \multicolumn{6}{|c|}{ Complexity grade } \\
\hline & Very difficult & Difficult & Moderate & Mild & Easy & Total \\
\hline Need & $69(29.6)$ & $63(27.0)$ & $45(19.3)$ & $56(24.0)$ & $0(0)$ & 233 \\
\hline No need & $0(0)$ & $0(0)$ & $1(0.3)$ & $117(30.9)$ & $261(68.9)$ & 379 \\
\hline Total & 69 & 63 & 46 & 173 & 261 & 612 \\
\hline$\chi^{2}=447.22, d f=4, P=0.00$ & & & & & & \\
\hline
\end{tabular}

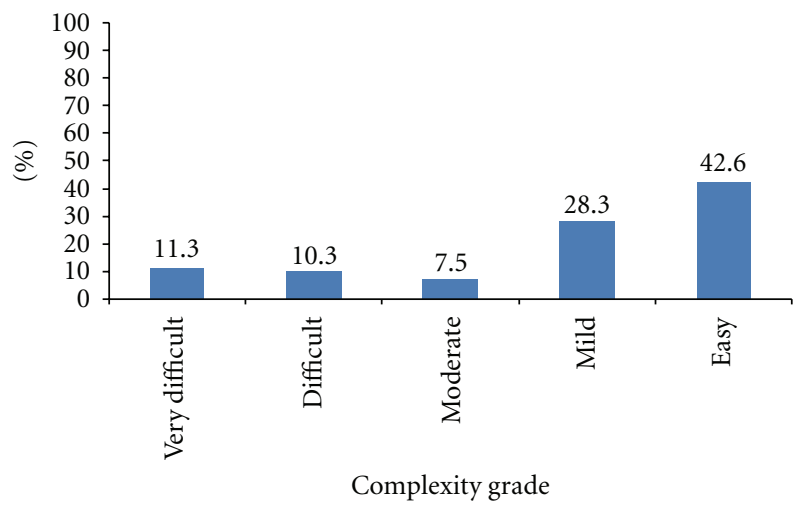

FIGURE 1: Complexity grades according to the Index of Complexity, Outcome, and Need.

with recognised needs for treatment that brought them to the orthodontists.

The increase of orthodontic treatment need with age seen in this study is probably due to the fact that untreated malocclusion worsens with age as the permanent occlusion becomes established [32]. When assessed professionally, male adolescents had a significantly greater need for treatment than females which is consistent with the findings of Burden et al. [33], but inconsistent with the finding by Onyeaso [20] in a clinic-based study in Southwest Nigeria where clinical research has shown that more females recognise a need for orthodontic treatment than males [20]. These findings, however, are in contrast to other studies to assess orthodontic treatment need using the ICON, DAI, and IOTN conducted in Nigeria [15, 29, 34], Tanzania [35], Senegal [27], France [1], Kuwait [36], Latvia [26], and Iran [28] where there were no gender or age differences.

Very difficult and difficult complexity grades of malocclusion accounted for almost a quarter of the adolescents $(21.6 \%)$ which was similar to values obtained in Iranian schoolchildren (26\%) [28] but in sharp contrast to that obtained among adolescents in Western Nigeria (9.9\%) [24] and $10 \%$ in Latvia [26]. The majority of adolescents with malocclusion can be greatly reduced by intercepting and treating during childhood. In the Iranian study [28], only $1.1 \%$ of the studied population wore an orthodontic appliance, which indicates a dearth of interceptive orthodontics among Iranian children. Such is the case in Rivers State, where none of the children wore an appliance, and it is just recently that such services started at the University of Port Harcourt Teaching Hospital in the State. Much higher values were obtained in previous clinic-based studies in Nigeria
[23], Greece [30], and United States [31] of $60.7 \%, 61 \%$ and $60 \%$, respectively, due to the fact that these are orthodontic patients with obvious needs for treatment.

Moderately complex cases in this study were the least in number $(7.5 \%)$ which is quite low compared with values from other prevalence studies, $16.1 \%$ in Nigeria [24], 14.1\% in Latvia [26], and $15.1 \%$ in Iran [28]. This value is also much lower than that obtained in clinic-based studies carried out in Nigeria [23] (14.3\%), Greece [30] (23\%), and USA [31] (22\%).

Mild and easy cases in our study $(70.9 \%)$ were found to be comparable to the $75 \%$ obtained in Western Nigeria [23] and 76\% obtained in Latvia [26], higher than 58.5\% amongst Iranian schoolchildren [28], but in contrast to values obtained among orthodontic patients in Nigeria [23] (25\%), Greece [30] (16\%), and USA [31] (18\%).

Another finding in this study was the significant difference in complexity grades found between male and female adolescents. Twice as many male students (15.1\%) had very difficult grades of complexity as compared with the female students $(7.7 \%)$. This is similar to the findings in the recent Iranian study [28], where a greater number of male $(14.8 \%)$ than female children $(9.1 \%)$ were found to have very difficult grades of complexity of their malocclusions although this was not statistically significant $(P>0.05)$, unlike the present study.

In this study there were also highly significant associations between orthodontic treatment complexity and need because the higher the complexity grade, the higher the degree of treatment need and the greater the severity of the malocclusion. Similar findings have been documented in both epidemiological studies and in orthodontic patient populations in earlier studies in Ibadan [23, 24] using the ICON and DAI and in a US study [25]. The complexity of cases in a particular location is extremely important because cases classified as very difficult, difficult, and moderate in complexity require the skills of specialists to be adequately treated. Richmond et al. [4, 37], as well as Onyeaso and BeGole [31], found the pretreatment ICON score to be a good indicator of treatment difficulty. They reported that cases with higher pretreatment ICON scores took a longer time to treat. Cassinelli et al. [5] reported that complexity or difficulty in achieving an ideal occlusion increases as the severity of the initial malocclusion increases.

\section{Conclusion}

The overall prevalence of orthodontic treatment need among adolescents aged 12-18 years in Rivers State, Nigeria was 
$38.1 \%$. Most of the subjects fell into the easy grade of complexity while about a quarter was found to have difficult and very difficult grades of complexity.

As the level of complexity of malocclusion increased, a corresponding increase in treatment need was seen. Although no adequate explanation was found, orthodontic treatment need and complexity were found to be significantly higher amongst males and in the older age group.

Considering the large percentages of adolescents found to have a need for orthodontic treatment as well as difficult and very difficult grades of treatment complexity, we recommend that more attention be given to the training of orthodontic specialists, and that orthodontic care should be subsidised by the Rivers State Government so that it can become affordable to the majority of these adolescents in need of such care.

\section{References}

[1] M. Souames, F. Bassigny, N. Zenati, P. J. Riordan, and M. L. Boy-Lefevre, "Orthodontic treatment need in French schoolchildren: an epidemiological study using the index of orthodontic treatment need," European Journal of Orthodontics, vol. 28, no. 6, pp. 605-609, 2006.

[2] P. H. Brook and W. C. Shaw, "The development of an index of orthodontic treatment priority," European Journal of Orthodontics, vol. 11, no. 3, pp. 309-320, 1989.

[3] N. C. Cons, J. Jenny, and F. J. Kohout, DAI: The Dental Aesthetic Index, University of Iowa, Iowa City, Iowa, USA, 1986.

[4] S. Richmond, N. A. S. Aylott, M. E. S. Panahei, B. Rolfe, W. Harzer, and E. Tausche, "A 2-center comparison of orthodontist's perceptions of orthodontic treatment dDifficulty," Angle Orthodontist, vol. 71, no. 5, pp. 404-410, 2001.

[5] A. G. Cassinelli, A. R. Firestone, F. M. Beck, and K. W. L. Vig, "Factors associated with orthodontists' assessment of difficulty," American Journal of Orthodontics and Dentofacial Orthopedics, vol. 123, no. 5, pp. 497-502, 2003.

[6] C. Daniels and S. Richmond, "The development of the index of complexity, outcome and need (ICON)," Journal of Orthodontics, vol. 27, no. 2, pp. 149-162, 2000.

[7] A. Richardson and J. R. Ana, "Occlusion and malocclusion in Lagos," Journal of Dentistry, vol. 1, no. 3, pp. 134-139, 1973.

[8] E. S. Akpata and D. Jackson, "Overjet values of children and young adults in Lagos," Community Dentistry and Oral Epidemiology, vol. 7, no. 3, pp. 174-176, 1979.

[9] M. C. Isiekwe, "Malocclusion in Lagos, Nigeria," Community Dentistry and Oral Epidemiology, vol. 11, no. 1, pp. 59-62, 1983.

[10] S. P. Aggarwal and S. A. Odusanya, "Orthodontic status of schoolchildren in Ile-Ife, Nigeria," Acta de Odontologia Pediatrica, vol. 6, pp. 9-12, 1985.

[11] O. D. Otuyemi and R. O. Abidoye, "Malocclusion in 12-yearold suburban and rural Nigerian children," Community Dental Health, vol. 10, no. 4, pp. 375-380, 1993.

[12] O. O. Dacosta, "The prevalence of malocclusion among a population of northern Nigeria school children," West African Journal of Medicine, vol. 18, no. 2, pp. 91-96, 1999.

[13] O. O. Sanu, "Occlusal variations in Nigerians of Yoruba ethnic group,” Nigerian Quarterly Journal of Hospital Medicine, vol. 10 , pp. 51-54, 2000.

[14] C. O. Onyeaso, "Prevalence of malocclusion among adolescents in Ibadan, Nigeria," American Journal of Orthodontics and Dentofacial Orthopedics, vol. 126, no. 5, pp. 604-607, 2004.
[15] O. D. Otuyemi, V. I. Ugboko, C. A. Adekoya-Sofowora, and K. C. Ndukwe, "Unmet orthodontic treatment need in rural Nigerian adolescents," Community Dentistry and Oral Epidemiology, vol. 25, no. 5, pp. 363-366, 1997.

[16] O. D. Otuyeml, A. Ogunyinka, O. Dosumu, N. C. Cons, and J. Jenny, "Malocclusion and orthodontic treatment need of secondary school students in Nigeria according to the dental aesthetic index (DAI)," International Dental Journal, vol. 49, no. 4, pp. 203-210, 1999.

[17] C. O. Onyeaso, "Orthodontic treatment need of mentally handicapped children in Ibadan, Nigeria, according to the dental aesthetic index," Journal of Dentistry for Children, vol. 70, no. 2, pp. 159-163, 2003.

[18] C. O. Onyeaso, "An assessment of relationship between selfesteem, orthodontic concern, and Dental Aesthetic Index (DAI) scores among secondary school students in Ibadan, Nigeria," International Dental Journal, vol. 53, no. 2, pp. 7984, 2003.

[19] C. O. Onyeaso, "Orthodontic treatment need and demand in a group of Nigerian adults: a teaching hospital-based study," Odonto-Stomatologie Tropicale, vol. 27, no. 107, pp. 32-36, 2004.

[20] C. O. Onyeaso, "Orthodontic treatment need of Nigerian outpatients assessed with the Dental Aesthetic Index," Australian Orthodontic Journal, vol. 20, no. 1, pp. 19-23, 2004.

[21] C. O. Onyeaso and G. A. Aderinokun, "The relationship between dental aesthetic index (DAI) and perceptions of aesthetics, function and speech amongst secondary school children in Ibadan, Nigeria," International Journal of Paediatric Dentistry, vol. 13, no. 5, pp. 336-341, 2003.

[22] C. O. Onyeaso and G. Idaboh, "Orthodontic treatment complexity and need at the University College Hospital, Ibadan, Nigeria, according to the Index of Complexity, Outcome and Need (ICON): a pilot study," Pediatric Dental Journal, vol. 16, pp. 128-131, 2006.

[23] C. O. Onyeaso, "Orthodontic treatment complexity and need in a group of Nigerian patients: the relationship between the Dental Aesthetic Index (DAI) and the Index of Complexity, Outcome, and Need (ICON)," The Journal of Contemporary Dental Practice, vol. 8, no. 3, pp. 37-44, 2007.

[24] C. O. Onyeaso, "Relationship between Index of Complexity, Outcome and Need and Dental Aesthetic Index in the assessment of orthodontic treatment complexity and need of Nigerian adolescents," Pesquisa Brasileira em Odontopediatria e Clinica Integrada, vol. 8, pp. 141-145, 2008.

[25] C. O. Onyeaso and E. A. Begole, "Relationship between index of complexity, outcome and need, dental aesthetic index, peer assessment rating index, and American Board of Orthodontics objective grading system," American Journal of Orthodontics and Dentofacial Orthopedics, vol. 131, no. 2, pp. 248-252, 2007.

[26] A. Liepa, I. Urtane, S. Richmond, and F. Dunstan, "Orthodontic treatment need in Latvia," European Journal of Orthodontics, vol. 25, no. 3, pp. 279-284, 2003.

[27] P. I. Ngom, F. Diagne, F. Dieye, K. Diop-Ba, and F. Thiam, "Orthodontic treatment need and demand in Senegalese school children aged 12-13 years: an appraisal using IOTN and ICON," Angle Orthodontist, vol. 77, no. 2, pp. 323-330, 2007.

[28] A. Borzabadi-Farahani and F. Eslamipour, "The relationship between the ICON index and Aesthetic Components of the IOTN Index," World Journal of Orthodontics, vol. 11, pp. 43$48,2010$.

[29] C. O. Onyeaso and M. O. Arowojolu, "Perceived, desired, and normatively determined orthodontic treatment needs among 
orthodontically untreated Nigerian adolescents," West African Journal of Medicine, vol. 22, no. 1, pp. 5-9, 2003.

[30] S. Richmond, C. Ikonomou, B. Williams, and B. Rolfe, "Orthodontic treatment standards in Greece," Hellenic Orthodontic Review, vol. 4, pp. 9-20, 2001.

[31] C. O. Onyeaso and E. A. BeGole, "Orthodontic treatment standard in an accredited graduate orthodontic clinic in North America assessed using the index of complexity, outcome and need (ICON)," Hellenic Orthodontic Review, vol. 9, pp. 23-24, 2006.

[32] C. O. Onyeaso and E. A. BeGole, "Associations between pretreatment age and treatment time with orthodontic treatment outcome: a comparison by means of two orthodontic indices," Hellenic Orthodontic Review, vol. 1, pp. 8-20, 2008.

[33] D. J. Burden, C. M. Mitropoulos, and W. C. Shaw, "Residual orthodontic treatment need in a sample of 15- and 16-yearolds," British Dental Journal, vol. 176, no. 6, pp. 220-224, 1994.

[34] C. O. Onyeaso and O. O. Sanu, "Perception of personal dental appearance in Nigerian adolescents," American Journal of Orthodontics and Dentofacial Orthopedics, vol. 127, no. 6, pp. 700-706, 2005.

[35] E. A. Mugonzibwa, A. M. Kuijpers-Jagtman, M. A. Van 't Hof, and E. N. Kikwilu, "Perceptions of dental attractiveness and orthodontic treatment need among Tanzanian children," American Journal of Orthodontics and Dentofacial Orthopedics, vol. 125, no. 4, pp. 426-433, 2004.

[36] H. Kerosuo, S. Al Enezi, E. Kerosuo, and E. Abdulkarim, "Association between normative and self-perceived orthodontic treatment need among Arab high school students," American Journal of Orthodontics and Dentofacial Orthopedics, vol. 125, no. 3, pp. 373-378, 2004.

[37] S. Richmond, C. Ikonomou, B. Williams, S. Ramel, B. Rolfe, and J. Kurol, "Orthodontic treatment standards in a public group practice in Sweden," Swedish Dental Journal, vol. 25, no. 4, pp. 137-144, 2001. 


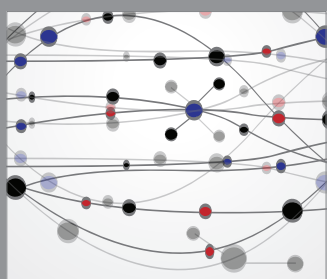

The Scientific World Journal
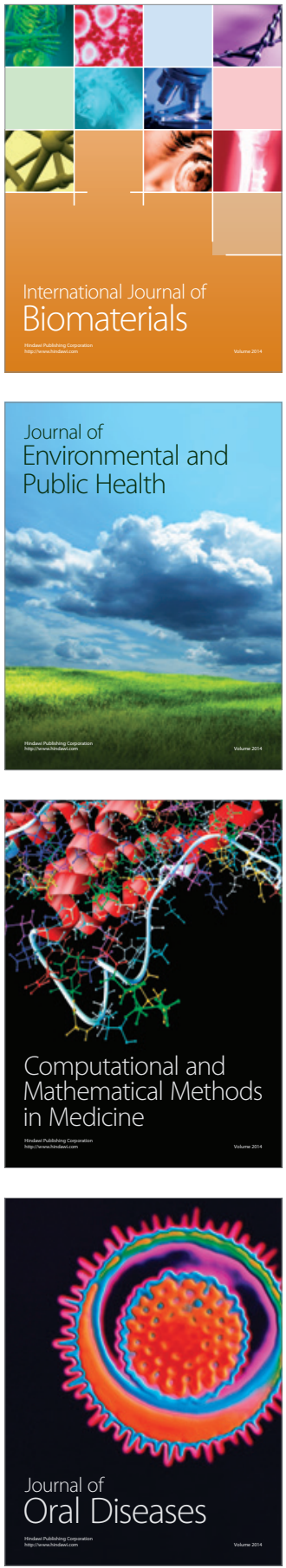
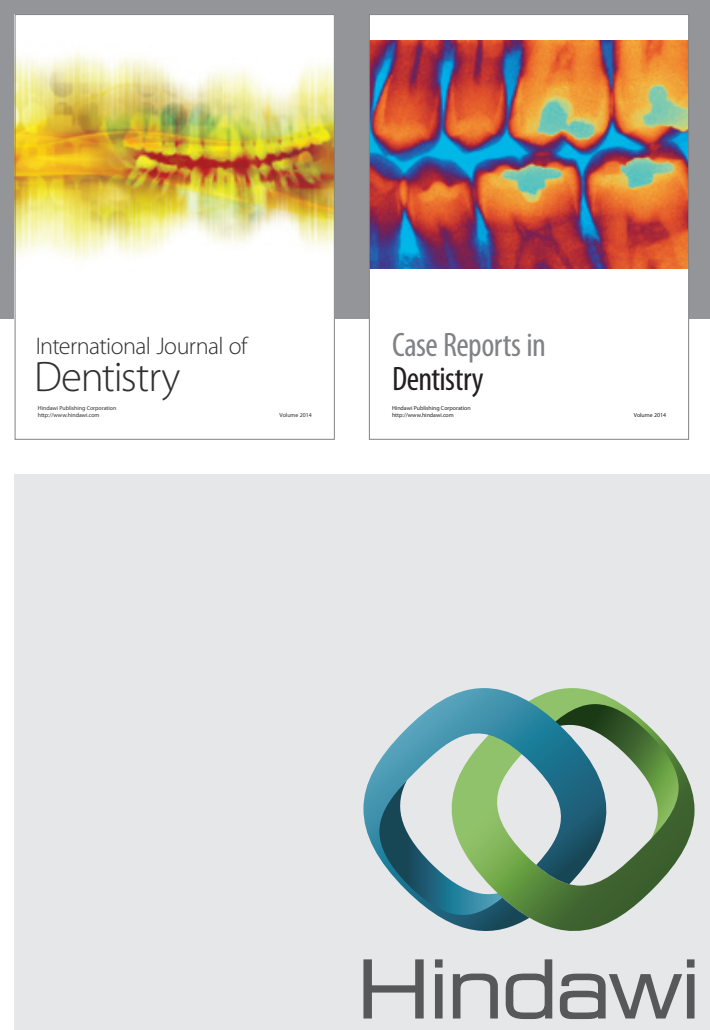

Submit your manuscripts at

http://www.hindawi.com
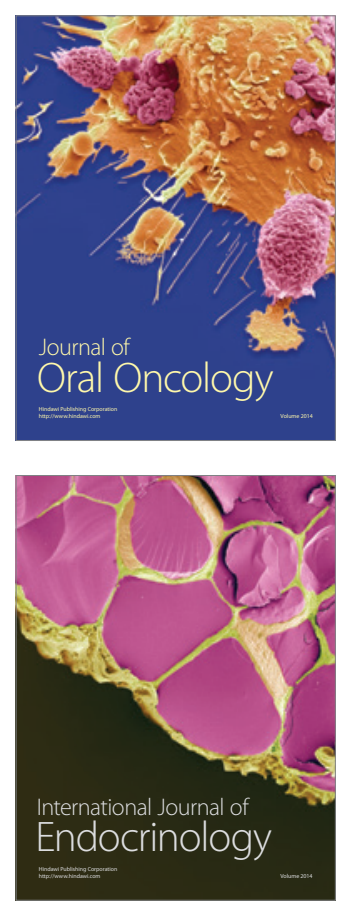
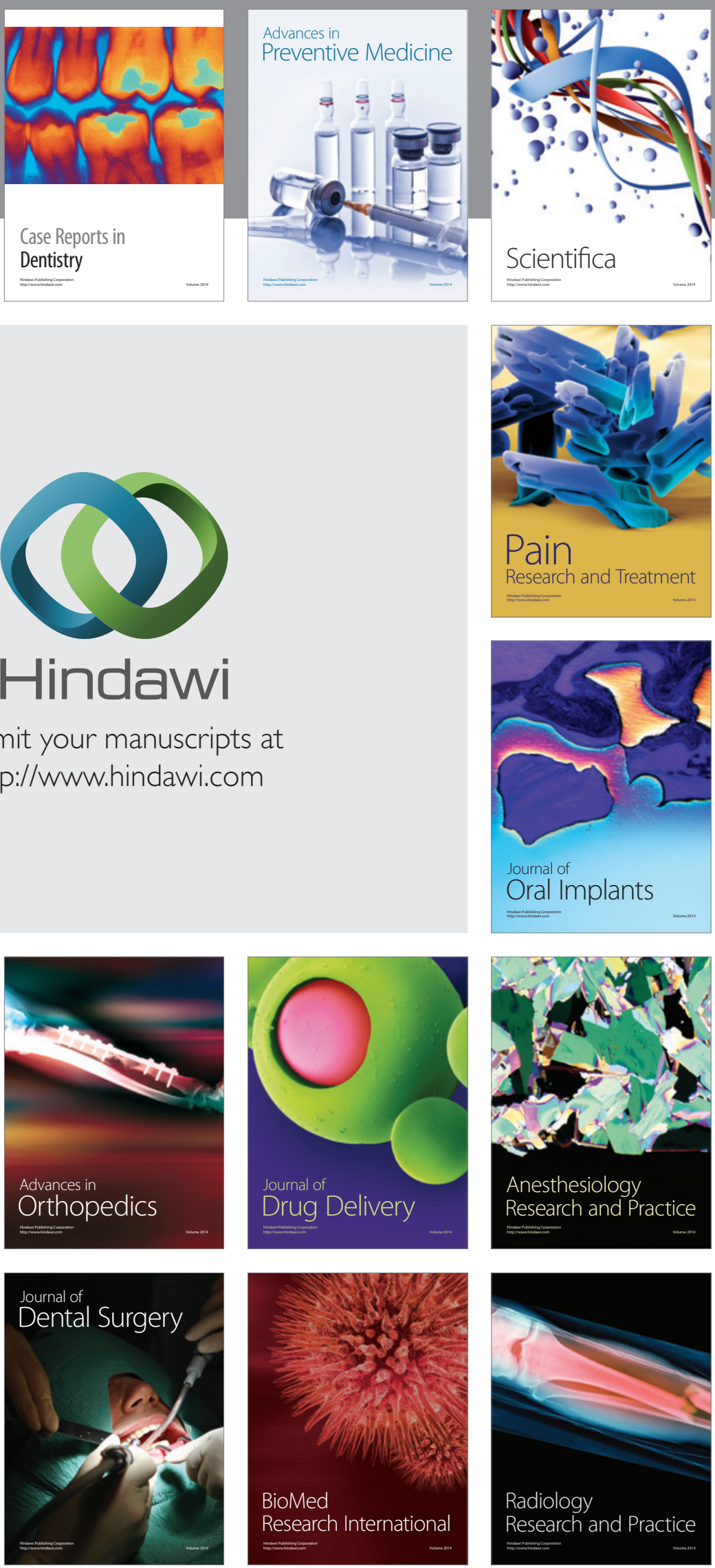